Supporting Information

\title{
Phase Equilibria for the Hydroaminomethylation of 1-Decene
}

Fabian Huxoll $^{1}$, Stefan Schlïter ${ }^{2}$, Robert Budde ${ }^{2}$, Mirko Skiborowski ${ }^{2, a}$, Marc Petzold ${ }^{3}$

Lutz Böhm³ , and Gabriele Sadowski ${ }^{1}$

${ }^{1}$ Laboratory of Thermodynamics, Department of Biochemical and Chemical Engineering, TU Dortmund University, Emil-Figge-Str. 70, 44227 Dortmund, Germany

${ }^{2}$ Laboratory of Fluid Separations, Department of Biochemical and Chemical Engineering, TU Dortmund University, Emil-Figge-Str. 70, 44227 Dortmund, Germany

${ }^{3}$ Chair of Chemical \& Process Engineering, TU Berlin, Ackerstr. 76, 13355 Berlin, Germany.

*Corresponding author: Gabriele Sadowski; gabriele.sadowski@tu-dortmund.de; Phone: +49 2317552635

aPresent address: Institute of Process Systems Engineering, Hamburg University of Technology, Am Schwarzenberg-Campus 4, 21073 Hamburg, Germany 


\section{S1. Soave-Redlich-Kwong Equation of State}

The amount of $\mathrm{H}_{2}$ in the gas phase at start of the experiment $\left(n_{\mathrm{H}_{2}, \text { start }}\right)$ and in equilibrium $\left(n_{\mathrm{H}_{2}, \text { eq }}\right)$ was evaluated using the Soave-Redlich-Kwong equation of state ${ }^{1}$ according to Graboski and Daubert ${ }^{2}$ :

$$
p=\frac{R \cdot T}{v-b}-\frac{a \cdot S}{v \cdot(v+b)}
$$

with:

$$
\begin{gathered}
a=\frac{0.42747 \cdot R^{2} \cdot T_{\mathrm{C}}^{2}}{p_{c}} \\
b=\frac{0.08664 \cdot R \cdot T_{\mathrm{c}}}{p_{c}} \\
S=\left(\begin{array}{c}
\left.1+\left(0.48508+155171 \cdot \omega-0.15613 \cdot \omega^{2}\right) \cdot\left(1-\sqrt{\frac{T}{T_{\mathrm{c}}}}\right)\right)^{2} \\
\frac{V}{v}=n
\end{array}\right.
\end{gathered}
$$

$T$ is the temperature, $R$ the universal gas constant, $v$ the molar volume of the gas phase, $\mathrm{V}$ the volume of the gas phase, and $n$ is the mole number of the gas. $T_{\mathrm{c}}$ and $p_{\mathrm{c}}$ are the critical temperature and critical pressure of the gas, respectively. $\omega$ is the acentric factor. For $\mathrm{H}_{2}$, Onnes et al. ${ }^{3}$ found $T_{\mathrm{c}}=33.18 \mathrm{~K}$ and $p_{\mathrm{c}}=13 \times 10^{5} \mathrm{~Pa}$, while McCarthy et al. ${ }^{4}$ determined the acentric factor to be $\omega=-0.219$.

Eqs S1-S4 were evaluated by numerical determination of $v$ in MATLAB for the starting pressure of the experiment and for the pressure after reaching the equilibrium.

The resulting difference in the amount of $\mathrm{H}_{2}$ in the gas phase $\left(\Delta n_{\mathrm{H}_{2}}\right)$ between start of the experiment $\left(n_{H_{2}, \text { start }}\right)$ and equilibrium $\left(n_{H_{2}, \text { eq }}\right)$ was used to calculate the mole fraction of the gas transferred into the liquid $\left(x_{\mathrm{H}_{2}}\right.$ ) (Eqs S5 and S6). It was assumed that the amount of gas in the 
liquid phase right at the start of the experiment and the one of the solvent in the gas phase could be neglected.

$$
x_{H_{2}}=\frac{n_{g H_{2}, e q}-n_{H_{2}, \text { start }}}{n_{H_{2}, \text { eq }}-n_{H_{2}, \text { start }}+n_{\text {liquid }}}=\frac{\Delta n_{H_{2}}}{\Delta n_{H_{2}}+n_{\text {liquid }}} .
$$




\section{S2. PCP-SAFT Pure-Component Parameter Fitting}

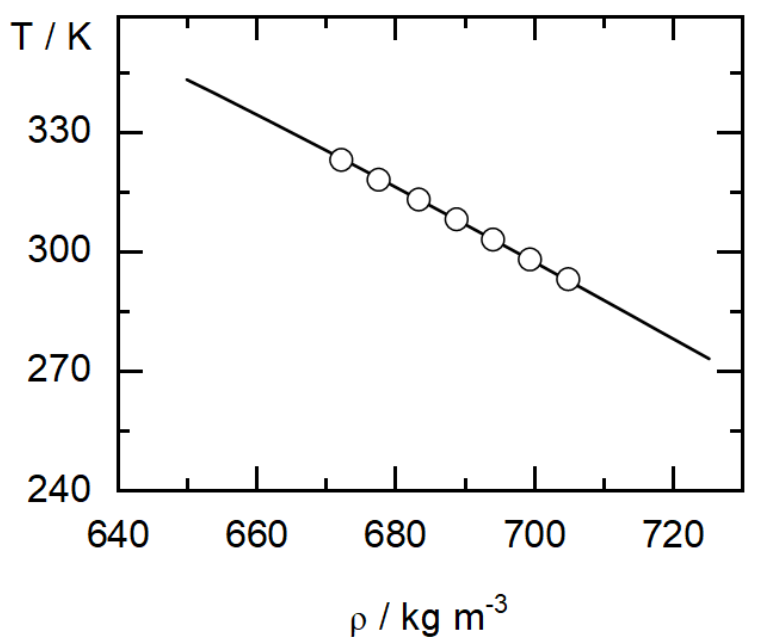

Figure S1. Liquid density of DEA at ambient pressure $(p=0.1 \mathrm{MPa})$. Symbols represent experimentally determined liquid densities from the literature. ${ }^{5}$ Solid lines are PCP-SAFT calculations using the pure-component parameters fitted in this work (Table 2).

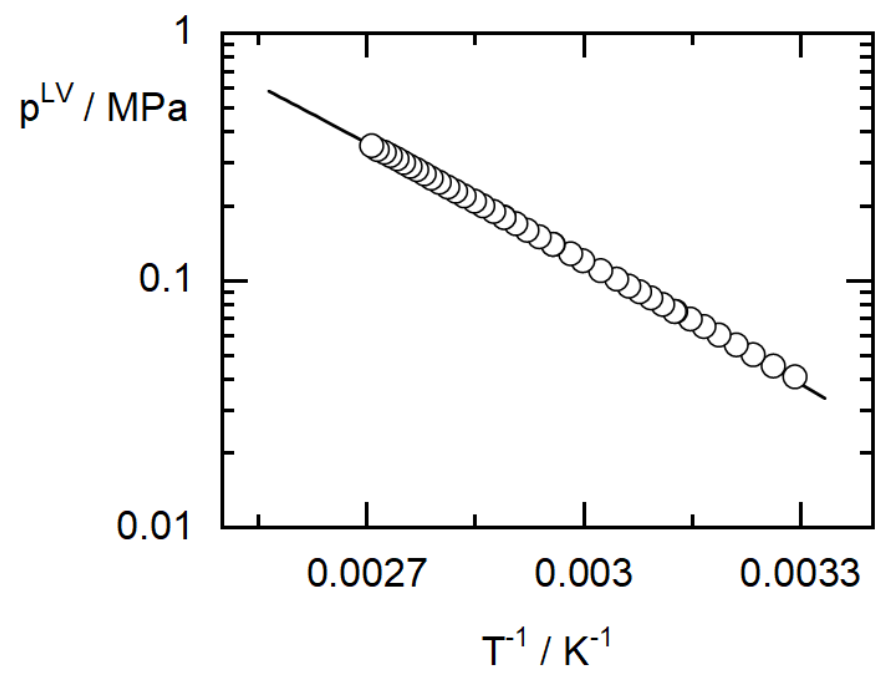

Figure S2. Vapor pressure of DEA. Symbols represent experimentally determined vapor pressures from the literature. ${ }^{6}$ Solid lines are PCP-SAFT calculations using the pure-component parameters fitted in this work (Table 2). 


\section{S3. Gas solubility}

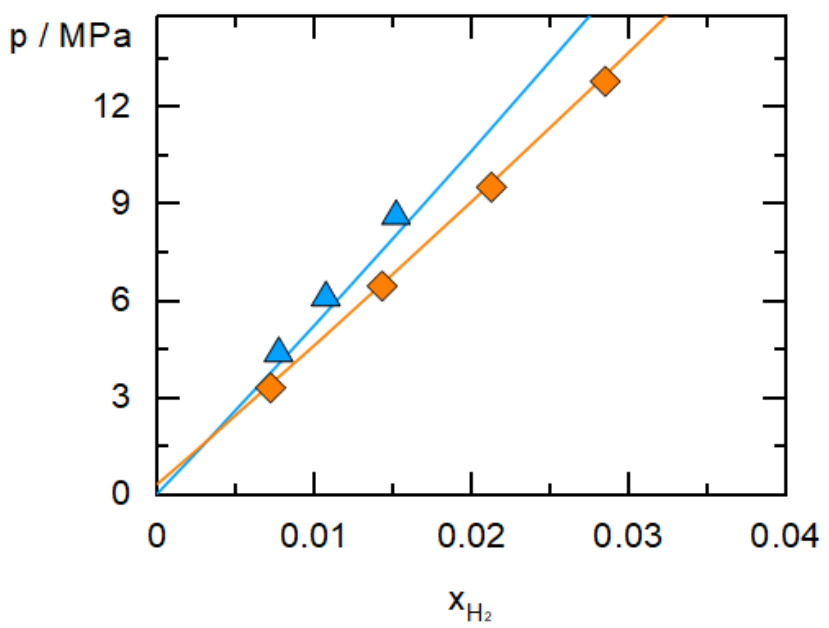

Figure S3. $\mathrm{H}_{2}$ mole fraction solubility in methanol as a function of pressure at different temperatures. Symbols represent experimental data from literature ${ }^{7}$ at $323.15 \mathrm{~K}$ (triangles) and $373.15 \mathrm{~K}$ (diamonds). The lines are PCP-SAFT modeling results using the parameters from Tables 2 and 3.

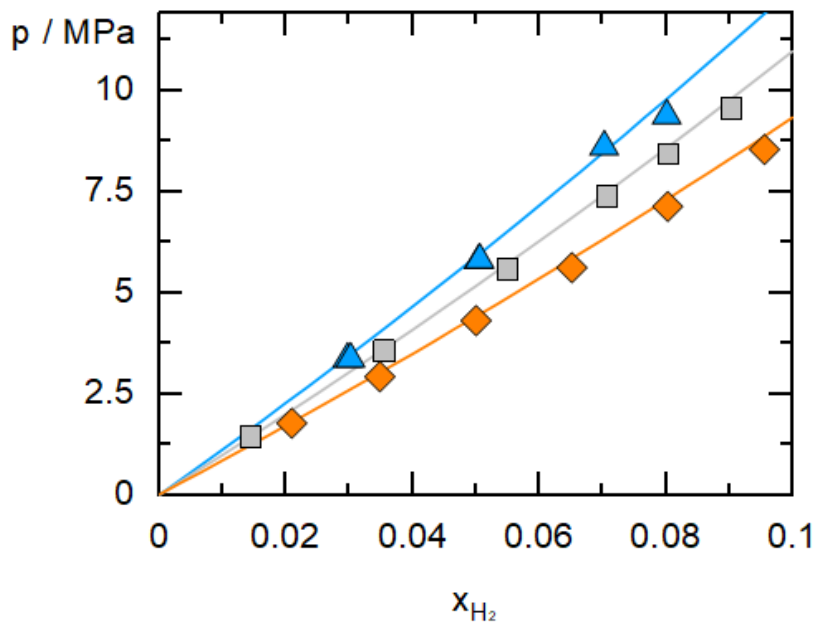

Figure S4. $\mathrm{H}_{2}$ mole fraction solubility in $n$-dodecane as a function of pressure at temperatures varying from 344.3 to $410.9 \mathrm{~K}$. Symbols represent experimental data from literature ${ }^{8}$ at 344.3 K (triangles), $377.60 \mathrm{~K}$ (squares) and 410.9 K (diamonds). The lines are PCP-SAFT modeling results using the parameters from Tables 2 and $\mathbf{3}$. 


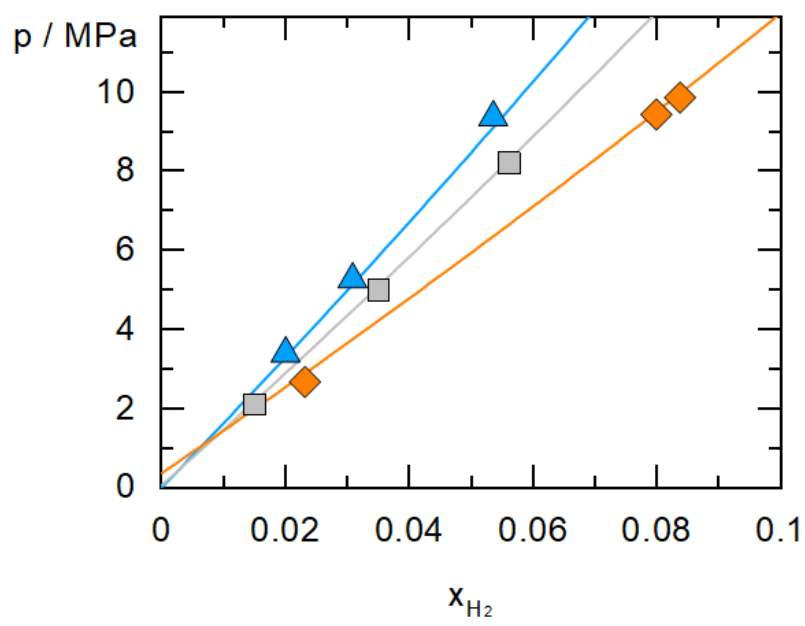

Figure S5. $\mathrm{H}_{2}$ mole fraction solubility in triethylamine as a function of pressure at temperatures varying from 293.15 to $373.15 \mathrm{~K}$. Symbols represent experimental data from literature ${ }^{9}$ at 293.15 K (triangles), $323.15 \mathrm{~K}$ (squares), and $373.15 \mathrm{~K}$ (diamonds). The lines are PCP-SAFT modeling results using the parameters from Tables 2 and 3. Due to the lack of experimental $\mathrm{H}_{2}$ solubility data in DEA we used the $\mathrm{H}_{2}$ solubility in trimethylamine instead.

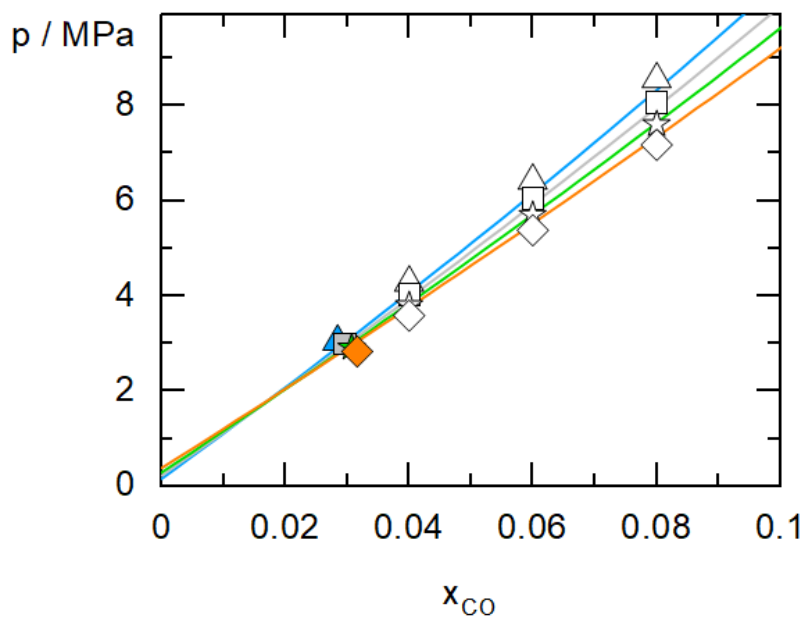

Figure S6. CO mole fraction solubility in DEA as a function of pressure at temperatures varying from 343 to $373 \mathrm{~K}$. Full symbols represent experimental data from literature ${ }^{10}$ at $343 \mathrm{~K}$ (triangles), $353 \mathrm{~K}$ (squares), $363 \mathrm{~K}$ (stars) and $373 \mathrm{~K}$ (diamonds). White symbols are data derived from given Henry's law constants. ${ }^{10}$ The lines are PCP-SAFT modeling results using the parameters from Tables $\mathbf{2}$ and $\mathbf{3}$. 


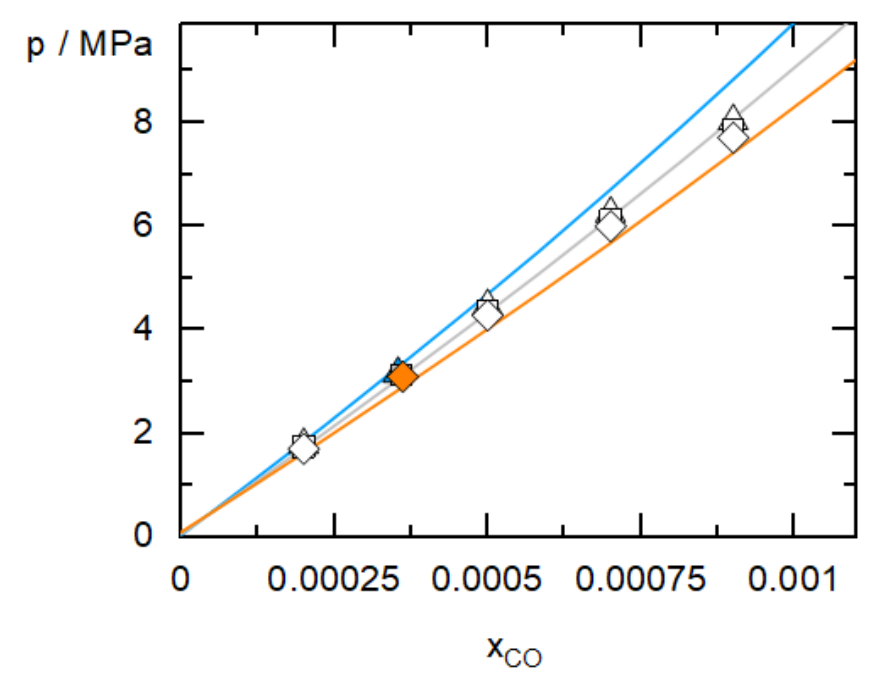

Figure S7. CO mole fraction solubility in water as a function of pressure at temperatures varying from 353 to $373 \mathrm{~K}$. Full symbols represent experimental data from literature ${ }^{10}$ at $323.15 \mathrm{~K}$ (triangles), $373.15 \mathrm{~K}$ (squares) and $423.15 \mathrm{~K}$ (diamonds). White symbols are data derived from given Henry's law constants. ${ }^{10}$ The lines are PCP-SAFT modeling results using the parameters from Tables 2 and 3 . 


\section{S4. VLE}

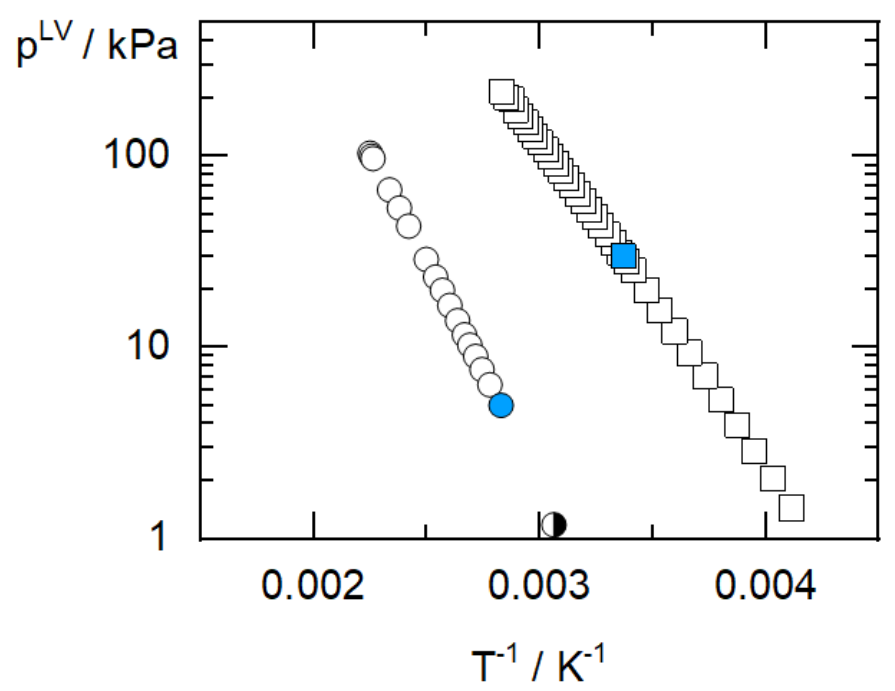

Figure S8: Vapor pressures of 1-decene and DEA. Available literature data of 1-decene (white circles $^{11}$ and half circles ${ }^{12}$ ) and DEA (white squares ${ }^{13}$ ) compared to the experimental results of this work (full symbols).

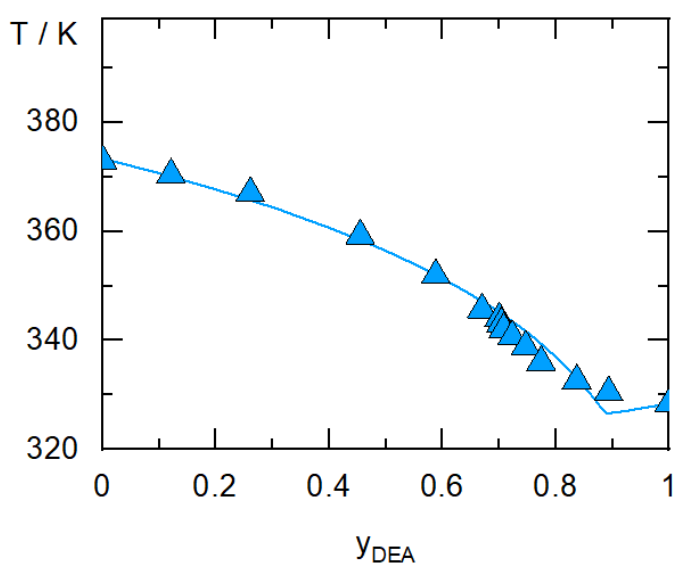

Figure S9: VLE of DEA with water at ambient pressure. The triangles are experimental dew points from literature. ${ }^{14}$ The line is a PCP-SAFT modeling results using the parameters from Tables 2 and 10. 


\section{S5. LLE}

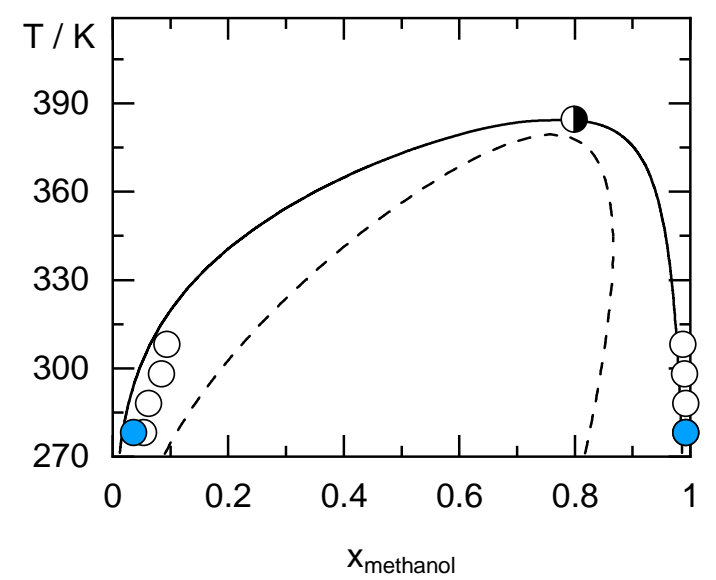

Figure S10. LLE of methanol with $n$-dodecane at ambient pressure ( $p=0.1 \mathrm{MPa}$ ). Symbols represent experimental data from Casás et al. (white circles) ${ }^{15}$ and Carrillo et al. (half circle) ${ }^{16}$ compared to the experimental results of this work (full circles) taken from Table 12. The solid lines are PC-SAFT modeling results using the $k_{i j}$ fitted in this work (Table 10) compared to a previous work. ${ }^{17}$ 


\section{References}

(1) Soave, G. Equilibrium constants from a modified Redlich-Kwong equation of state. Chem. Eng. Sci. 1972, 27, 1197-1203.

(2) Graboski, M. S.; Daubert, T. E. A Modified Soave Equation of State for Phase Equilibrium Calculations. 1. Hydrocarbon Systems. Ind. Eng. Chem. Proc. Des. Dev. 1978, 17, 443-448.

(3) Onnes, H. K.; Crommelin, C. A.; Cath, P. G. Isothermals of di-atomic substances and their binary mixtures. XIX. A preliminary determination of the critical point of hydrogen. Proc. K. Ned. Akad. Wet. 1918, 20, 178-184.

(4) McCarty, R. D.; Hord, J.; Order, H. M. NBS Monograph 168:Selected Properties of Hydrogen (Engineering Design Data); National Bureau of Standards: Boulder, CO, 1981.

(5) Almasi, M.; Nasim, H. Thermodynamic and transport properties of binary mixtures; friction theory coupled with PC-SAFT model. J. Chem. Thermodyn. 2015, 89, 1-6.

(6) Aucejo, A.; Loras, S.; Munoz, R.; Wisniak, J.; Segura, H. Phase Equilibria and Multiple Azeotropy in the Associating System Methanol + Diethylamine. J. Chem. Eng. Data 1997, 42, 1201-1207.

(7) Brunner, E.; Hültenschmidt, W.; Schlichthärle, G. Fluid mixtures at high pressures IV. Isothermal phase equilibria in binary mixtures consisting of (methanol + hydrogen or nitrogen or methane or carbon monoxide or carbon dioxide). J. Chem. Thermodyn. 1987, 19, 273-291.

(8) Gao, W.; Robinson, R. L.; Gasem, K. A. M. High-Pressure Solubilities of Hydrogen, Nitrogen, and Carbon Monoxide in Dodecane from 344 to $410 \mathrm{~K}$ at Pressures to 13.2 MPa. J. Chem. Eng. Data 1999, 44, 130-132.

(9) Brunner, E. Löslichkeit von Wasserstoff in Aminen. Ber. Bunsen. Phys. Chem. 1978, 82, 798-805.

(10) Khan, M. M. T.; Halligudi, S. B. Solubility of carbon monoxide in aqueous mixtures of allyl alcohol, diethylamine, and triethylamine. J. Chem. Eng. Data 1988, 33, 276-278.

(11) Forziati, A. F.; Camin, D. L.; Rossini, F. D. Density, refractive index, boiling point, and vapor pressure of eight monoolefin (1-alkene), six pentadiene, and two cyclomonoolefin hydrocarbons. J. Res. Natl. Bur. Stan. 1950, 45, 406. 
(12) Setkina, V. N. Reactions of Decomposition and Substitution Among Quternary Ammonium Compounds V. Dehydrative Acetion of Ammonium Derivatives and the Role of Oxonium Comp. in Dehydration React. of Alcohlols. Izv. Akad. Nauk SSSR, Ser. Khim. 1950, 216-222.

(13) Wolff, H.; Bauer, O.; Goetz, R.; Landeck, H.; Schiller, O.; Schimpf, L. Association and vapor pressure isotope effect of variously deuterated methanols in n-hexane. J. Phys. Chem. 1976, 80, 131-138.

(14) Frangieh, M. R.; Bougrine, A. J.; Tenu, R.; Dhenain, A.; Counioux, J. J.; Goutaudier, C. Evolution of the Liquid-Vapor Equilibrium Properties of Several Unsymmetrical Amines:

Determination of Their Binary Isobaric Diagrams and Applications to the Distillation. J. Chem. Eng. Data 2013, 58, 576-582.

(15) Casás, L. M.; Touriño, A.; Orge, B.; Marino, G.; Iglesias, M.; Tojo, J. Thermophysical Properties of Acetone or Methanol + n -Alkane (C 9 to C 12 ) Mixtures. J. Chem. Eng. Data 2002, 47, 887-893.

(16) Carrillo, E.; Talanquer, V.; Costas, M. Wetting Transition at the Liquid-Air Interface of Methanol-Alkane Mixtures. J. Phys. Chem. 1996, 100, 5888-5891.

(17) Lemberg, M.; Sadowski, G. Phase Equilibria for the Hydroesterification of 10-Undecenoic Acid Methyl Ester. J. Chem. Eng. Data 2016, 61, 3317-3325. 